Review

\title{
Linear Skin Defects with Multiple Congenital Anomalies (LSDMCA): An Unconventional Mitochondrial Disorder
}

\author{
Alessia Indrieri ${ }^{1,2}$ (D) and Brunella Franco ${ }^{1,3, *}$ \\ 1 Telethon Institute of Genetics and Medicine (TIGEM), Via Campi Flegrei, 34, 80078 Pozzuoli, Naples, Italy; \\ indrieri@tigem.it \\ 2 Institute for Genetic and Biomedical Research (IRGB), National Research Council (CNR), 20090 Milan, Italy \\ 3 Medical Genetics, Department of Translational Medical Sciences, University of Naples "Federico II", \\ Via Sergio Pansini 5, 80131 Naples, Italy \\ * Correspondence: franco@tigem.it; Tel.: +39-081-1923-0615
}

Citation: Indrieri, A.; Franco, B. Linear Skin Defects with Multiple Congenital Anomalies (LSDMCA): An Unconventional Mitochondrial Disorder. Genes 2021, 12, 263. https://doi.org/10.3390/ genes12020263

Academic Editor: Roel Ophoff

Received: 18 December 2020

Accepted: 9 February 2021

Published: 11 February 2021

Publisher's Note: MDPI stays neutral with regard to jurisdictional claims in published maps and institutional affiliations.

Copyright: (c) 2021 by the authors. Licensee MDPI, Basel, Switzerland. This article is an open access article distributed under the terms and conditions of the Creative Commons Attribution (CC BY) license (https:/ / creativecommons.org/licenses/by/ $4.0 /)$.

\begin{abstract}
Mitochondrial disorders, although heterogeneous, are traditionally described as conditions characterized by encephalomyopathy, hypotonia, and progressive postnatal organ failure. Here, we provide a systematic review of Linear Skin Defects with Multiple Congenital Anomalies (LSDMCA), a rare, unconventional mitochondrial disorder which presents as a developmental disease; its main clinical features include microphthalmia with different degrees of severity, linear skin lesions, and central nervous system malformations. The molecular basis of this disorder has been elusive for several years. Mutations were eventually identified in three X-linked genes, i.e., HCCS, COX7B, and NDUFB11, which are all endowed with defined roles in the mitochondrial respiratory chain. A peculiar feature of this condition is its inheritance pattern: X-linked dominant male-lethal. Only female or XX male individuals can be observed, implying that nullisomy for these genes is incompatible with normal embryonic development in mammals. All three genes undergo X-inactivation that, according to our hypothesis, may contribute to the extreme variable expressivity observed in this condition. We propose that mitochondrial dysfunction should be considered as an underlying cause in developmental disorders. Moreover, LSDMCA should be taken into consideration by clinicians when dealing with patients with microphthalmia with or without associated skin phenotypes.
\end{abstract}

Keywords: MLS/MIDAS/LSDMCA; X-inactivation; HCCS; COX7B; NDUFB11; mitochondrial disorders; mitochondrial respiratory chain; microphthalmia; linear skin defects

\section{Introduction: An Historical Perspective}

In the early 1990s, females with a specific phenotypic combination of short stature with developmental abnormalities, including microphthalmia and linear skin defects of the face and neck, were reported. In these cases, abnormalities of the short arm of the $X$-chromosome resulted in monosomy of the Xp22.3 region [1]. In males, the lack of distal $X p$ results in contiguous gene syndromes characterized by the appearance of recessive traits underlain by a number of genes disrupted by the X-chromosome abnormalities. However, apart from eight males showing a 46 XX karyotype and a translocation Xp/Yp, no males with the typical ocular and skin phenotype have been described to date. The condition defined by the clinical features observed in females was denominated Microphthalmia with Linear Skin defects (MLS) syndrome (MIM \# 309801). Given the presence of aborted fetuses in familial cases and the absence of males with X-chromosomal rearrangements and a classical MLS phenotype, it was defined as an X-linked dominant male-lethal trait (alternatively named Microphthalmia Dermal Aplasia and Sclerocornea (MIDAS)). This condition was subsequently demonstrated to be genetically heterogeneous and, following identification of three responsible genes, has been renamed Linear Skin Defects with Multiple Congenital Anomalies (LSDMCA) 1, 2, and 3 (OMIM \# 309801, OMIM \# 300887, and OMIM \# 300952), respectively. 
Deletion mapping combined with a positional candidate gene strategy allowed the identification of the first disease gene, HCCS (holocytochrome c synthase; OMIM \# 300056), from the Xp22.2 region in 2006 [2]. Subsequently, in 2012, a candidate gene strategy led to the identification of mutations in COX7B (cytochrome c oxidase subunit 7B; OMIM \# 300805) localized to Xq21.1 [3]. Finally, in 2015, whole-exome sequencing facilitated the detection of point mutations in NDUFB11 (NADH-ubiquinone oxidoreductase 1 beta, subcomplex 11; OMIM \# 300403) from the Xp11.3 region [4], thus placing all the causative genes so far identified for this disease on the $\mathrm{X}$ chromosome. The disorder is quite rare; to date, a total of 82 affected individuals, plus four aborted and molecularly diagnosed fetuses, have been described. The majority of cases account for LSDMCA1 and are associated with abnormalities of distal Xp (70 cases with Xp22 translocation/terminal deletion/small or large interstitial deletions). In addition, point mutations in the HCCS gene have also been described. The remaining cases consist of point mutations in COX7B and NDUFB11 (see Table 1).

Table 1. Summary of point mutations identified to date in LSDMCA.

\begin{tabular}{|c|c|c|c|c|c|c|c|}
\hline Gene & $\begin{array}{c}\text { Gene } \\
\text { OMIM\# }\end{array}$ & Nucleotide Change & $\begin{array}{c}\text { Type of } \\
\text { Mutation }\end{array}$ & Predicted Protein & $\begin{array}{l}\text { Disease } \\
\text { Symbol }\end{array}$ & $\begin{array}{l}\text { Disease } \\
\text { OMIM\# }\end{array}$ & Ref \\
\hline HCCS & 300056 & $\begin{array}{c}\text { c. } 589 \mathrm{C}>\mathrm{T} \\
\text { c. } 649 \mathrm{C}>\mathrm{T} \\
\text { c. } 475 \mathrm{G}>\mathrm{A} \\
\text { c. }\left[=/ 524 \_525 \mathrm{del} A \mathrm{G}\right]\end{array}$ & $\begin{array}{l}\text { Nonsense } \\
\text { Missense } \\
\text { Missense } \\
\text { Frameshift }\end{array}$ & $\begin{array}{c}\text { p.R197*a } \\
\text { p.R217C } \\
\text { p.E159K } \\
\text { p.[=/E175Vfs*30] }\end{array}$ & $\begin{array}{c}\text { MLS/ } \\
\text { MIDAS } \\
\text { MCOPS7 } \\
\text { LSDMCA1 }\end{array}$ & 309801 & {$[2,13,14]$} \\
\hline COX7B & 300885 & $\begin{array}{c}\text { c. } 196 \mathrm{delC} \\
\text { c. } 41-2 \mathrm{~A}>\mathrm{G} \\
\text { c. } 55 \mathrm{C}>\mathrm{T}\end{array}$ & $\begin{array}{l}\text { Frameshift } \\
\text { Frameshift } \\
\text { Nonsense }\end{array}$ & $\begin{array}{l}\text { p.L66Cfs*48 } \\
\text { p.V14Gfs*19 } \\
\text { p.E19* }\end{array}$ & LSDMCA2 & 300887 & [3] \\
\hline NDUFB11 & 300403 & $\begin{array}{l}\text { c. } 262 C>T \\
\text { c. } 402 \mathrm{delG}\end{array}$ & $\begin{array}{l}\text { Nonsense } \\
\text { Frameshift }\end{array}$ & $\begin{array}{c}\text { p.Arg88* } \\
\text { p.Arg134Serfs*3 }\end{array}$ & LSDMCA3 & 300952 & [4] \\
\hline
\end{tabular}

a This mutation was identified in two different patients (see also Table S1). Ref, references.

Notably, there is still room for additional causative genes as mutation analysis has demonstrated that not all reported cases can be explained by the causative genes so far described (BF, unpublished).

\section{The Molecular Basis of LSDMCA}

As mentioned, the majority of LSDMCA1 patients carry rearrangements of the Xp region and are females. Exceptions to this observation are represented by eight male individuals showing $46 \mathrm{XX}$ karyotypes and translocations involving the short arms of the $\mathrm{X}$ and $\mathrm{Y}$ chromosomes and resulting in $\mathrm{Xp}$ monosomy in one of two $\mathrm{X}$ chromosomes [5]. A complete list of chromosomal abnormalities associated with LSDMCA1 is reported in Table S1. The LSDMCA1 critical region was defined by characterization of patients with deletions and translocations involving the short arm of the $X$ chromosome $[6,7]$ and spans approximately $610 \mathrm{~Kb}$ in Xp22.2. The region contains three genes: MID1, which has been shown to be responsible for X-linked Opitz syndrome [8]; HCCS, which encodes for the mitochondrial holocytochrome c-type synthase (known as heme lyase) that catalyzes the covalent attachment of heme to both apo-Cytochrome (Cyt) c and c1 [9,10], and ARHGAP6 [11]. In 2002, it was shown that deletions involving the syntenic LSDMCA1 critical region in the mouse led to embryonic lethality, which could be rescued by overexpression of the human holocytochrome c-type synthase, indicating HCCS as the most convincing candidate gene for LSDMCA1 [12].

However, the most conclusive evidence was derived from analysis of the few LSDMCA cases not associated with chromosomal abnormalities [2-4]) (Tables 1 and S1). First, point mutations and a small deletion were identified in HCCS, thus providing the evidence that this gene is indeed responsible for LSDMCA1 [2]. Specifically, de novo heterozygous point mutations, i.e., a nonsense mutation (c.589C > T/p.R197*) which was subsequently 
identified in an additional case [13] and a missense mutation (c.649C > T/p.R217C), were identified in two patients showing a normal karyotype [2]. Later, a novel missense mutation (c.475G > A/p.E159K) was identified in a sporadic case with bilateral microphthalmia and sclerocornea without skin lesions, indicating that the phenotypic variability described in LSDMCA1 is not correlated to the extent of the Xp deletion [14]. Finally, a mosaic 2-bp HCCS deletion, (c.[=/524_525delAG] (p.[=/E175Vfs*30]), was identified in a patient with unilateral ocular anomalies and no skin defects [13]. This patient showed a variable degree of mosaicism that may have contributed to her mild phenotype. However, a patient with a mosaic X-chromosomal rearrangement showed the classical LSDMCA1 phenotype [15], indicating that other mechanisms are responsible for the high clinical variability in patients with HCCS mutations.

HCCS is a highly conserved, nuclear-encoded mitochondrial protein, located on the outer surface of the inner mitochondrial membrane, where it catalyzes the covalent attachment of heme to both Cytochrome (Cyt) c and c1 $[9,10]$. Cytc1 is an integral component of the mitochondrial respiratory chain (MRC) complex III and transfers electrons to Cytc, which, in turn, shuttles them from complex III to IV. In Saccharomyces cerevisiae, two heme lyases exist, Cyc3 and Cyt2, responsible for heme incorporation into Cytc and Cytc1, respectively [16]. Inactivation of either Cyc3 or Cyt2 results in loss of respiratory growth [17,18]. Conversely, in higher eukaryotes, a single heme lyase, HCCS, is sufficient for Cytc and Cytc1 maturation $[9,16]$. Functional studies have demonstrated that the point mutations interfere with the role of HCCS in mitochondrial function and exert their pathogenic effect via oxidative phosphorylation (OXPHOS) impairment [19]. Moreover, conditional inactivation of Hccs in the murine heart and its downregulation in medaka fish result in severe OXPHOS defects, thus definitively demonstrating a key role for this protein in MRC formation and function $[19,20]$.

Although HCCS is an ubiquitous protein, the phenotype observed in LSDMCA1 is restricted to specific organs, suggesting that its dosage/function may be critical in selected tissues. A critical role for HCCS in the control of apoptosis activation has been described. In the intrinsic programmed cell death pathway, mitochondrial outer membrane permeabilization leads to the release of Cytc that binds cytosolic Apaf1 and recruits and activates the initiator caspase-9 to form the apoptosome complex [21,22]. Moreover, other proapoptotic proteins, such as SMAC/DIABLO and Omi/HtrA2, are released in the cytosol and bind inhibitors of apoptosis (IAPs), relieving their inhibitory effects on caspase activity [23]. In injured adult rat motor neurons, Hccs migrates from mitochondria to the cytosol under apoptotic stimuli, resulting in suppression of the X-linked inhibitor of apoptosis (XIAP) protein and activation of caspase-3, indicating that the cytosolic HCCS may act, similarly to SMAC/DIABLO and Omi/HtrA2, as an IAP binding protein [24]. Interestingly, downregulation of hccs in medaka fish leads to increased cell death via apoptosome-independent caspase- 9 activation, which occurs in the mitochondria and is triggered by OXPHOS defects and overproduction of reactive oxygen species (ROS). Notably, the activation of this pathway specifically occurs in the brain and eyes and underlies the development of microphthalmia and microcephaly observed in LSDMCA1 [19]. On the other hand, increased cell death was not detected in the hearts of HCCS deficient models (mice and fish) whereas decreased cardiomyocyte proliferation was observed in $\mathrm{Hccs}^{+/-}$mutant hearts $[19,20]$.

Almost all LSDMCA cases (without chromosomal abnormalities) show skewed Xchromosome inactivation, which suggests that there is a selective disadvantage for cells carrying the mutated allele on their active X [25]. Moreover, the increased cell death observed in the central nervous system (CNS) [19] and the reduced proliferation of Hccs-deficient cardiomyocytes [20] suggest that the tissue-specific activation of different molecular pathways may cause some of the phenotypes observed in LSDMCA patients, explaining the specificity of the defects observed. On the other hand, the influence of $\mathrm{X}$-inactivation remains the best explanation for the high degree of clinical variability observed in LSDMCA patients. 
After the discovery of HCCS mutations, more recent data have also implicated the $X$-linked COX7B and NDUFB11 genes in the pathogenesis of this genetic disorder. Interestingly, these genes are key components of the MRC complexes IV and I, respectively.

$C O X 7 B$ is a small gene comprising three exons on $\mathrm{Xq21.1}$. It is ubiquitously expressed and encodes an integral component of the cytochrome c oxidase (COX), the MRC complex IV [26,27]. In humans, COX is composed of three proteins encoded by the mitochondrial DNA (mtDNA) (COX1, COX2, and COX3) that assemble with 10 nuclear-encoded proteins (COX4, COX5A, COX5B, COX6A, COX6B, COX6C, COX7A, COX7B, COX7C, and COX8) to form the mature holo-complex [28].

In 2012, pathogenic point mutations in COX7B were found in LSDMCA patients with normal karyotypes and no mutations in HCCS [3]. In particular, a heterozygous 1-bp deletion in exon 3 (c.196delC/p.L66Cfs*48), a heterozygous splice mutation in intron 1 (c.41-2A > G/p.V14Gfs*19), and a heterozygous nonsense mutation in exon 2 (c.55C > $\mathrm{T} / \mathrm{p} . \mathrm{G} \ln 19^{*}$ ) were identified [3] (see Table 1). These mutations result in a truncated protein, which is predicted to lack the functional domain necessary for interaction with other subunits of the COX complex [3]. Although the MRC complex IV has been extensively studied, the function of COX7B within this complex has only been characterized after the discovery of the mutations leading to LSDMCA2. Notably, it has been shown that the small COX7B subunit is necessary for COX activity, COX assembly, and mitochondrial respiration [3]. Moreover, downregulation of $c 0 x 7 B$ in medaka fish resulted in increased cell death, leading to microcephaly and microphthalmia, thus resembling the phenotype observed in hccs-defective fish [3,29]. These data indicate an essential function for complex IV activity in vertebrate CNS development [3].

NDUFB11 is located on Xp11.23 and comprises three exons. Moreover, this gene is ubiquitously expressed and encodes for one of the 30 supernumerary subunits of NADH:ubiquinone oxidoreductase, the MRC complex I [30,31]. This complex is the largest within the MRC and is composed of around 45 subunits in mammals, seven of which are encoded by mtDNA. Only 14 proteins represent the core subunits and are essential for energy transduction [31,32].

In 2015, a heterozygous nonsense mutation (c.262C > T/p.Arg88*) and a heterozygous 1-bp deletion leading to frameshift (c.402delG/p.Arg134Serfs*3) in NDUFB11 were described in LSDMCA patients [4] (see Table 1). The authors also showed that NDUFB11 is necessary for the assembly of complex I membrane arm, for the maturation of the holocomplex, and for complex I-dependent mitochondrial respiration [4]. Interestingly, NDUFB11 knockdown in HeLA cells caused impaired cell growth and increased apoptosis [4], also shown in in vivo models of HCCS and COX7B downregulation $[19,29]$.

\section{The Clinical Spectrum of LSDMCA}

The characterization of patients has facilitated a thorough description of the clinical spectrum observed in this condition. Table S1 depicts all the LSDMCA cases reported to date, with descriptions of the commonly observed clinical findings, which are summarized in Table 2.

Linear skin lesions. The most constant and archetypal clinical feature is represented by the linear skin lesions. These are present in the majority of cases, regardless of the underlying causative mutation (77\% of LSDMCA1 with Xp22 rearrangements, $40 \%$ of cases with HCCS point mutations, $100 \%$ of LSDMCA2 and $67 \%$ of LSDMCA3 patients) (Table 2). They are commonly seen at birth as irregular linear erythematous patches, sometimes covered by hemorrhagic crusts. The skin marks are usually located on the face, particularly the cheeks, and the neck, with an asymmetric distribution and often extending to the chin and the nose (Figure 1). 
Table 2. Summary of clinical findings found in LSDMCA. Extended details can be found in Table S1.

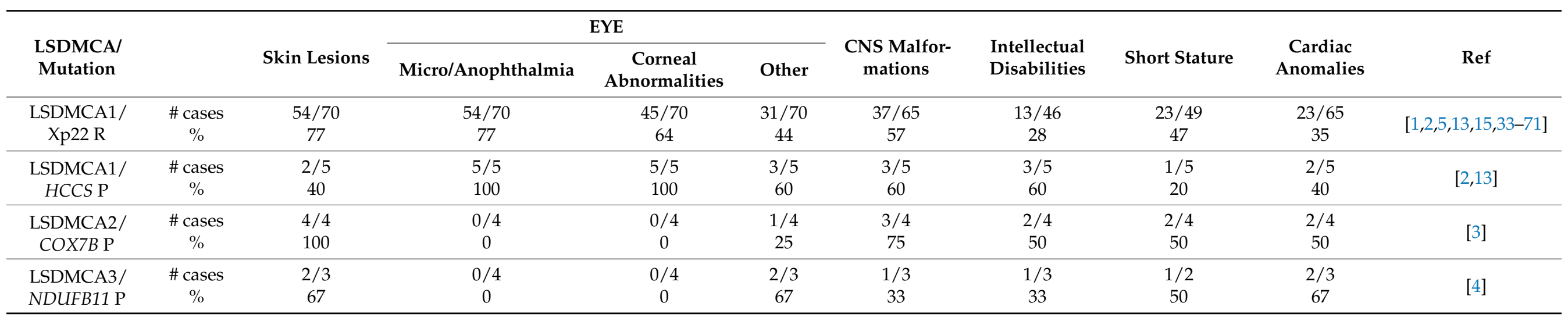

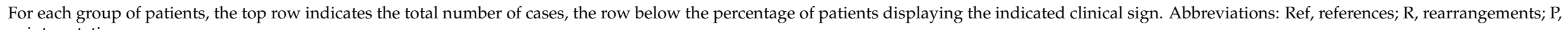
point mutations.
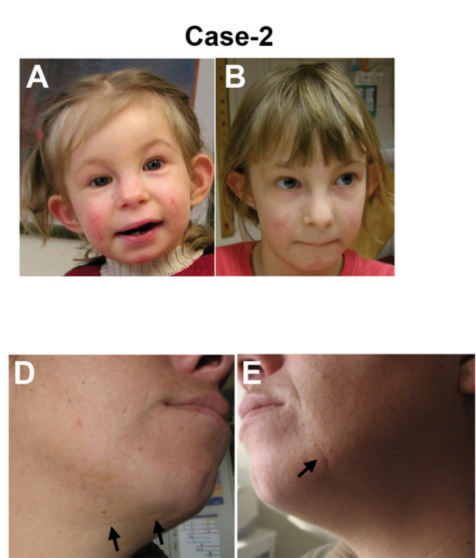

C
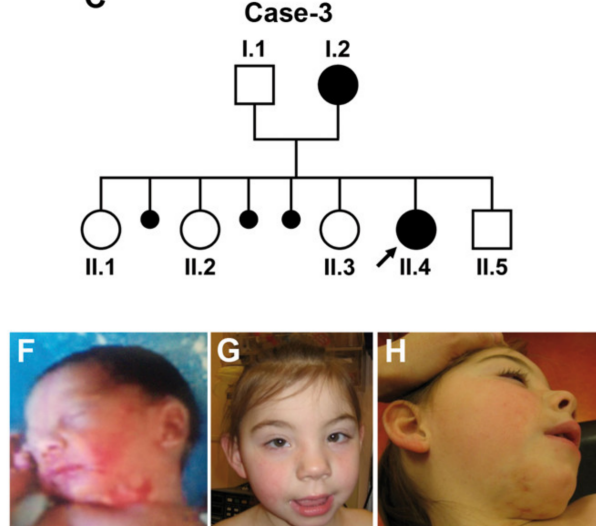

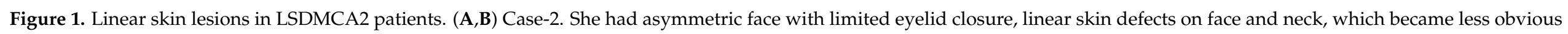

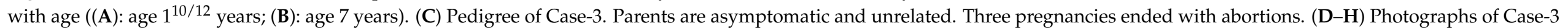

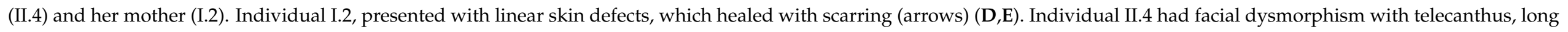

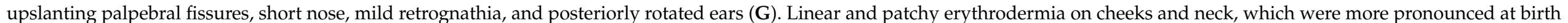

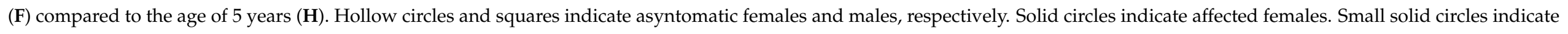
aborted fetuses. Figure from [3] used with permission. 
The same lesions can rarely be seen on the hands and other parts of the body. The cutaneous signs follow Blaschko lines and tend to improve over time, leaving minimal to no residual scars. Histopathological investigation revealed a thin, atrophic epidermis lacking rete ridges with a significant infiltrate of lymphocytes. In addition, irregular bundles of smooth muscle were observed in the deep dermis while adnexal structures were missing [49]. In a different study, dermatoscopic examination demonstrated erythematous areas with telangiectasias accompanied by an absence of sebaceous glands and vellus hairs, thus confirming the histopathological findings [64]. Notably, all investigations performed on the cutaneous wounds were done on LSDMCA1 patients. However, in all genetic forms of the disease, the skin lesions are similar in appearance, evolution, and localization, suggesting a similar patho-mechanism. In line with the ectodermal nature of this condition, affected individuals may also present nail dystrophy and spared hair. Notably, $10 \%$ of patients with primary mitochondrial disorders may present with skin symptoms given the importance of the mitochondrial energy metabolism in skin homeostasis [72].

Ocular findings. Microphthalmia is only observed in LSDMCA1 and can affect one or both eyes. It is observed in 77\% of LSDMCA1 with Xp22 rearrangements and 100\% of cases with HCCS point mutations (Table 2). The phenotype can be very severe and progress to anophthalmia. Additional ocular findings include sclerocornea (unilateral or bilateral), corneal opacity, prolapsed iris, orbital cysts, cornea plana, hypoplasia of the optic nerve, aphakia, anterior eye chamber defects, coloboma, microcornea, hypopigmented and disorganized retinal pigmented epithelium, cataracts, choroidal thickening, chorioretinopathy, glaucoma, lens abnormalities, aniridia, pale optic disk, and altered visual-evoked potential. As shown in Tables 2 and S1, additional ocular signs can be seen also in LSDMCA2 and 3, although they are more common in LSDMCA1.

Central nervous system (CNS) involvement. Regardless of the underlying genetic cause, the CNS is frequently implicated (in $~ 60 \%$ of LSDMCA1 cases, in the majority of LSDMCA2 patients, and in 1/3 LSDMCA3 cases) with a variety of clinical signs and symptoms. CNS anomalies include agenesis or hypoplasia of the corpus callosum, abnormal myelination, colpocephaly, seizures, hydrocephalus, ventriculomegaly, cysts, malformation of the septum pellucidum, and occult spinal dysraphism. Anencephaly has been described in a few cases (mainly aborted fetuses). Microcephaly can be observed as well as psychomotor developmental delay/intellectual deficits. Autistic behavior was described in a case with a 12.9-Mb Xp terminal deletion. Attention-deficit/hyperactivity disorder (ADHD) was diagnosed in a child with a point mutation in COX7B (see Table S1).

Cardiac findings. Heart abnormalities are observed in all forms of LSDMCA. They have occurred in $36 \%$ of LSDMCA1, in two individuals with point mutations in COX7B, and in two cases with point mutations in NDUFB11. Clinical features include atrioventricular septal defects, patent ductus arteriosum, coarctation of the aorta, patent foramen ovale, ventricular tachycardia, atrioventricular block, histiocytoid cardiomyopathy, poor contraction of the left ventricle, and eosinophilic cell infiltration. The two patients with point mutations in $C O X 7 B$ displayed tetralogy of Fallot and ventricular hypertrophy, pulmonary hypertension, and atrial septal defect [3]. Finally, patients bearing point mutations in NDUFB11 presented with histiocytoid cardiomyopathy and dilated cardiomyopathy and needed heart transplantation at the age of 6 months [4]. Notably, mutations in NDUFB11 have also been described in patients affected only by histiocytoid cardiomyopathy without features of LSDMCA [73,74], in a male infant with lethal mitochondrial complex 1 deficiency [75] and in sideroblastic anemia [76,77].

Other clinical findings include diaphragmatic hernia, which may also result in respiratory distress, and short stature. Facial dysmorphisms, genitourinary defects (intersexual genitalia, hypoplastic genitalia, imperforate or displaced anus and polycystic ovary syndrome), and skeletal abnormalities are mainly seen in LSDMCA1 cases with Xp22 rearrangements, possibly due to the involvement of other genes responsible for X-linked disorders [8,78-82]. An exception to this observation is represented by a patient displaying a point mutation in $C O X 7 B$ presenting with an asymmetric face with limited eyelid 
closure, a small chin, left renal agenesis, and ureteral duplication of the right kidney [3]. Figure 1 depicts the typical linear skin lesions and some of the facial dysmorphism observed in LCDMCA.

Variable expressivity in LSDMCA. Extensive variability in the phenotypic expressivity, ranging from very mild or no phenotype to severe clinical manifestations, has been described between individuals and even within the same family. Several examples are available for LSDMCA1. Allanson and Richter described a female with typical skin and ocular clinical manifestations whose mother, bearing the same Xp-terminal deletion, was healthy, except for areas of depigmented skin on the shoulder and the leg, which were recognized only after examination with ultraviolet light [71]. More recently, Vergult et al. reported a familial case in which both the mother and the daughter presented a submicroscopic deletion of $185-220 \mathrm{~kb}$ on Xp22.2. Both patients presented microphthalmia that in the mother was severe and required eye enucleation. Instead, the skin lesions were only observed in the mother, who also suffered three spontaneous abortions of unknown sex within the first trimester [67]. Moreover, it should be noted that in LSDMCA1, the severity of the phenotype is not strictly related to the extent of the Xp-chromosome deletion that represents the underlying genetic cause in the majority of cases. Molecular characterization indeed demonstrated that patients with very large deletion of distal $\mathrm{Xp}$, such as patient 2 from Lindsay et al., show a mild phenotype [1] while patients with point mutations in HCCS display the full phenotype $[2,13]$ (Table S1). A specific patient only displayed the typical linear skin defects, presented a 46,X,del (X) (pter-p22.2) karyotype, and was referred to the genetics clinic following the abortion of an anencephalic female fetus with the same karyotype [1]. Concerning LSDMCA2, only four cases have been reported to date. However, in the described familial case, a heterozygous nonsense mutation in the COX7B was identified in individual II.4 and her mother. The former presented the classical skin lesions, microcephaly, facial dysmorphisms, tetralogy of Fallot, clinodactyly of the fifth finger, intellectual disabilities, CNS malformation, poor vision, and ophthalmologic findings. Meanwhile, the mother only displayed the skin phenotype, a mild myopia, and had reported three pregnancies that ended with spontaneous abortions of unknown sex within the first trimester [3]. Lastly for LSDMCA3, only four cases have been reported and three are from a familial case. Subject 2 showed the typical linear skin lesions, ocular findings not including microphthalmia or sclerocornea, severe developmental delay, short stature, microcephaly, severe hypotonia, delayed dentition, brain malformations, and dilated cardiomyopathy that required heart transplantation. The mother, in whom the same mutation was identified, was completely asymptomatic. In the next pregnancy, ultrasound examination diagnosed a female fetus with a severe cardiological and neurological phenotype and intrauterine growth retardation that led to termination of pregnancy. Molecular studies identified the same frameshift mutation found in both the mother and subject 2 [4].

Concerning the possibility that the type of mutation could have an effect on the variability of the phenotype observed in LSDMCA, with the exception of those found in HCCS, all mutations identified in COX7B and NDUFB11 are frameshift or premature STOP codon (see Table 1) [3,4] that most likely represent loss-of-function mutations. Similarly, the two missense mutations involving highly conserved amino acids identified in HCCS (Table 1) [2,19] display a loss-of-function effect given their inability to complement a S. cerevisiae strain deficient for the HCCS orthologous gene product [19].

In particular, for $C O X 7 B$, the c.196delC mutation leads to the generation of a $\mathrm{COOH}-$ terminal truncated protein with the insertion of 46 novel amino acids. This mutant form is predicted to lack the domain that interacts with the two COX subunits, namely COX4 and COX6C $[3,26]$. The heterozygous splice mutation $(c .41-2 A>G)$ creates a novel splice acceptor site, leading to the production of out-of-frame transcripts and most likely to the formation of a truncated protein with 18 novel amino acids at the $\mathrm{COOH}$-terminal region [3]. Finally, the heterozygous c.55C $>\mathrm{T}$ nonsense mutation may result either in a functional null allele as result of nonsense-mediated mRNA decay or in a protein lacking a large C-terminal portion ( $\triangle \mathrm{aa} 19-80)$ [3]. Notably, this mutation has been identified in the 
patient and her healthy mother [3], suggesting that the severity of the LSDMCA phenotype is not due to the consequence of different mutations identified in COX7B, and implying that other mechanisms are responsible for the high clinical variability observed in LSDMCA.

Similarly, the two point mutations identified in NDUFB11, i.e., 262C $>$ T and c.402delG, are predicted to lead to the introduction of a premature stop codon and to a frameshift, respectively [4]. The latter mutation (p.Arg134Serfs $* 3$ ) was identified in a patient, a severely malformed fetus, and their healthy mother and was also identified in patients with histiocytoid cardiomyopathy without skin manifestations, further confirming the absence of a genotype/phenotype correlation [4,73]. Finally, heterozygous and hemizygous mutations in NDUFB11 were also associated with other X-linked conditions [75-77,83]. Notably, all females carry a loss-of-function heterozygous variant, whereas males carry a hemizygous missense or in-frame deletion, indicating that residual activity of NDUFB11 is needed for males to be viable [83].

\section{The Role of X-Chromosome and X-Chromosome Inactivation}

All the genes so far involved in this rare genetic condition, i.e., HCCS, $C O X 7 B$, and NDUFB11, are localized on the $\mathrm{X}$ chromosome. This segment of our genome has many peculiar features, including X-chromosome inactivation (XCI), also known as "lyonization". This phenomenon consists of the transcriptional silencing of one of the two $X$ chromosomes in female mammals to achieve dosage compensation between sexes [84]. This epigenetic process starts at the blastocyst stage in the early phases of embryo development. In normal conditions, the choice of which of the two $\mathrm{X}$ chromosomes is to be silenced is random but is then maintained in the progeny cells. Thus, in normal conditions, the ratio of the two-cell population (carrying the active and the inactive $X$, respectively) is around 50:50. As a consequence, normal female individuals are naturally mosaic and display organs with a mixed population of cells in which either the paternal or the maternal $X$ has been inactivated. For this reason, women are less susceptible to pathogenic variants on the active $X$ chromosome as the variant will not be expressed in all cells [85]. This explains why LSDMCA female patients can be observed while nullisomy for these genes in the hemizygous males is lethal as affected fetuses do not survive and are aborted. On the contrary, in diseased conditions, when one of the $\mathrm{X}$ chromosomes displays a mutation, the choice of which of the two chromosomes will be silenced is not random: the normal $\mathrm{X}$ chromosome is favored and the mutated $\mathrm{X}$ is preferentially inactivated. In this case, we have a divergence from the 50:50 ratio that is known as skewing of the XCI that can occur with variable degrees (Figure 2). The extensive intrafamilial and interfamilial phenotypic variability observed in this condition can be explained by Xinactivation. We hypothesize that in the affected heterozygous females, once the XCI process takes place in the early stages of embryo development, cells inactivating the normal $\mathrm{X}$ chromosome will die as a consequence of loss-of-function mutations in HCCS, COX7B, or NUFB11, on the transcriptionally active $\mathrm{X}$ chromosome $[25,86]$. We propose therefore that the clinical signs observed in LSDMCA would be the consequence of the different capabilities of the diverse tissues and organs to remove the "affected dying" cells by cell selection. According to our hypothesis, individuals characterized by a mild phenotype or even the total absence of clinical manifestations are the result of a completely skewed inactivation that obligates preferential inactivation of the mutated $X$ chromosome, leaving the non-mutated, transcriptionally active $\mathrm{X}$ in blood cells and tissues (e.g., eyes and skin). Conversely, the most severe clinical manifestations can be found in patients in which the mutated $X$ chromosome is active while the non-mutated one is transcriptionally silenced in tissues affected by the disease and/or at determined developmental stages (Figure 2). 


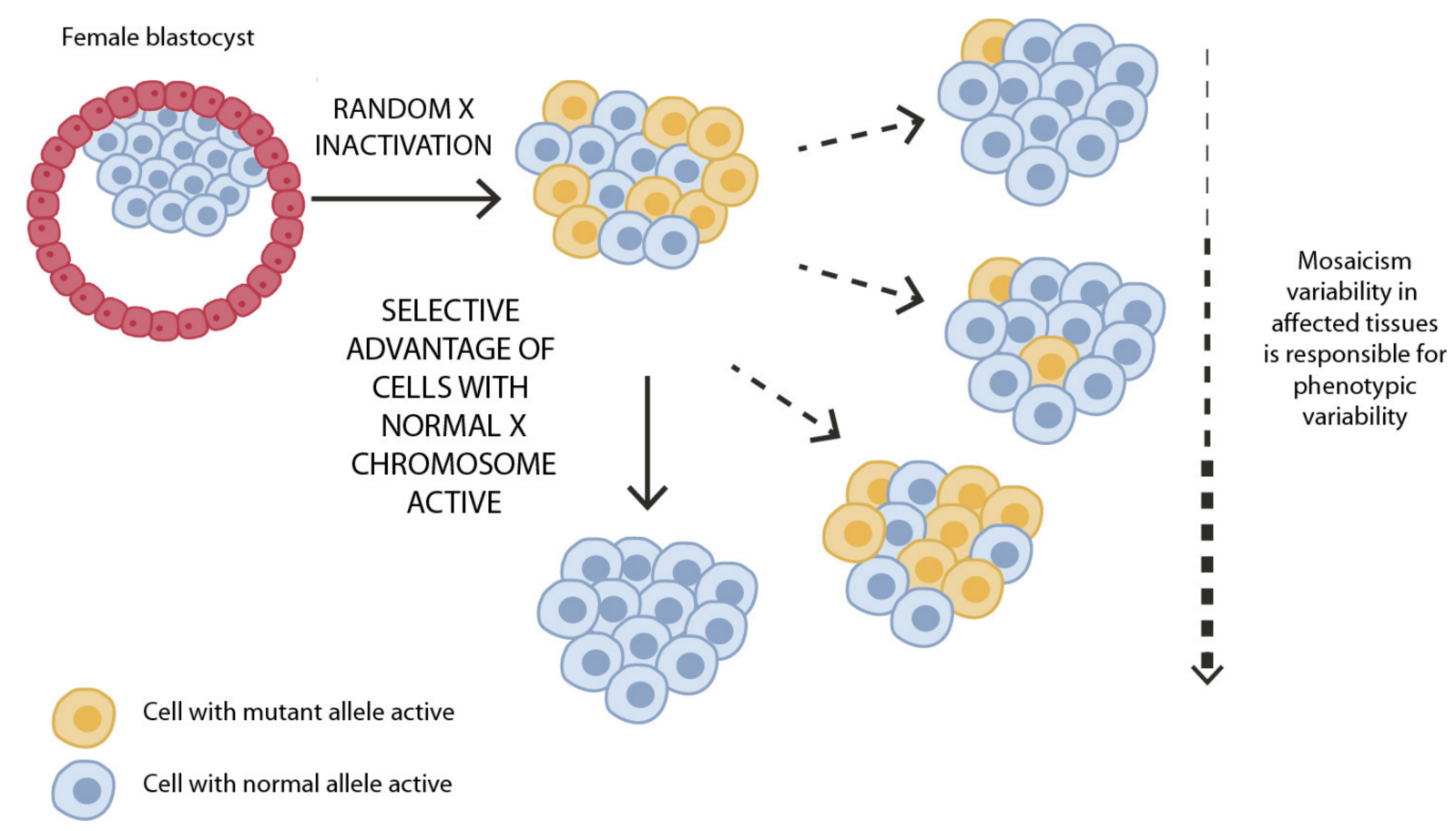

Figure 2. Schematic representation of XCI in female somatic cells. In normal conditions, the ratio of the two cell types (carrying the active and the inactive $\mathrm{X}$ chromosome) is approximately 50:50, but in females with X-linked dominant disorders, this ratio may be different, due to a potential disadvantage for cells expressing a mutant $\mathrm{X}$-linked allele. Divergence from the 50:50 ratio, known as skewing of XCI, can be different in various tissues, in different developmental stages, and may vary among individuals, causing variability in the severity of the phenotype observed. For disorders such as LSDMCA, affected females usually have totally skewed patterns of XCI, in favor of an active wild-type X chromosome.

\section{LSDMCA as an Unconventional Mitochondrial Disorder}

Mitochondrial diseases are a clinically heterogeneous group of rare disorders resulting from an MRC dysfunction. HCCS, COX7B, and NDUFB11 encode proteins necessary for the proper function of the MRC, thus defining LSDMCA as a mitochondrial disorder.

Although clinically heterogeneous, the typical features of mitochondrial diseases include neuromuscular hypotonia, ataxia, encephalopathy, encephalomyopathy, and various myopathies [87-89]. Interestingly, as previously described, LSDMCA patients show diverse phenotypes, mainly characterized by developmental defects affecting the eyes and the skin and, in this regard, LSDMCA represents an unconventional mitochondrial disease. LSDMCA represents a remarkable example of a truly developmental phenotype associated with mitochondrial dysfunction. Although neurological disorders and cardiac defects are common features of mitochondrial disorders, the unique skin lesions mainly affecting the head and neck and the microphthalmia are difficult to assign to deficiency of mitochondrial enzymes. Interestingly, HCCS was the first human gene encoding for an MRC protein which causes microphthalmia when mutated. Moreover, the skin involvement observed in mitochondrial diseases is atypical and can include hirsutism and hypertrichosis, as described in Leigh syndrome (OMIM \# 256000), and twisted hairs as reported in Bjornstad syndrome (OMIM \# 262000) [90].

HCCS, COX7B, and NDUB11 are all ubiquitously expressed since they are required for the OXPHOS pathway. However, the phenotypic manifestations observed in LSDMCAaffected females mainly affect the CNS. The remarkable involvement of the CNS is not surprising when considering the necessity for this high-energy-demand system to preserve adequate mitochondria number and function, a process which is termed mitostasis [91].

More recently, patients with NDUFB11 mutations displaying more classical mitochondrial phenotypes have been described $[75,83]$. These patients show a combination of neurological symptoms, muscle hypotonia, myopathy, lactic acidosis, histiocytoid car- 
diomyopathy, and sideroblastic anemia. Interestingly, these patients are all males carrying a missense or one amino acid in-frame deletion variants [83]. This observation indicates that some residual activity of the NDUFB11 protein may explain the less severe phenotype and is needed for males to be viable.

It is possible that differential tissue sensitivity to mitochondrial ATP depletion (high versus low energy demand) and/or overproduction of reactive oxygen species might elicit different molecular responses in the absence of HCCS, COX7B, or NDUFB11 in selected tissues and may therefore induce the blockages to cell replication and/or increased cell death. In addition, although the main function of the mitochondrion is the production of energy in the form of ATP, it is well known to have a central role in the regulation of the intrinsic pathway of cell death, a key process required for proper development of the CNS $[92,93]$. Deregulation of these processes and X-chromosome inactivation could function together to select OXPHOS-proficient cells, thus attenuating or abolishing MRC defects in the surviving tissues and individuals.

Nevertheless, additional studies are required to better understand the peculiarity of the LSDMCA phenotype that, to date, represents a unique example of a mitochondrial disease mainly characterized by an apoptosis-driven developmental phenotype.

Supplementary Materials: The following are available online at https:/ / www.mdpi.com/2073-442 5/12/2/263/s1, Table S1. Extended clinical description of LSDMCA cases.

Author Contributions: A.I. and B.F. drafted, revised, and approved the manuscript. All authors have read and agreed to the published version of the manuscript.

Funding: This research was funded by the Italian Telethon Foundation.

Data Availability Statement: Data sharing not applicable.

Acknowledgments: We thank the Italian Telethon Foundation for continuous support and Sandro Banfi and Manuela Morleo for critical reading of the manuscript. We also thank all the clinicians, researchers, patients, and patient's families who contributed to the dissection of this rare and intriguing condition.

Conflicts of Interest: The authors declare no conflict of interest.

\section{References}

1. Lindsay, E.A.; Grillo, A.; Ferrero, G.B.; Roth, E.J.; Magenis, E.; Grompe, M.; Hultén, M.; Gould, C.; Baldini, A.; Zoghbi, H.Y.; et al. Microphthalmia with linear skin defects (MLS) syndrome: Clinical, cytogenetic and molecular characterization. Am. J. Med. Genet. 1994, 49, 229-234. [CrossRef] [PubMed]

2. Wimplinger, I.; Morleo, M.; Rosenberger, G.; Iaconis, D.; Orth, U.; Meinecke, P.; Lerer, I.; Ballabio, A.; Gal, A.; Franco, B.; et al. Mutations of the Mitochondrial Holocytochrome c-Type Synthase in X-Linked Dominant Microphthalmia with Linear Skin Defects Syndrome. Am. J. Hum. Genet. 2006, 79, 878-889. [CrossRef] [PubMed]

3. Indrieri, A.; Van Rahden, V.A.; Tiranti, V.; Morleo, M.; Iaconis, D.; Tammaro, R.; D'Amato, I.; Conte, I.; Maystadt, I.; Demuth, S.; et al. Mutations in COX7B cause microphthalmia with linear skin lesions, an unconventional mitochondrial disease. Am. J. Hum. Genet. 2012, 91, 942-949. [CrossRef] [PubMed]

4. Van Rahden, V.A.; Fernandez-Vizarra, E.; Alawi, M.; Brand, K.; Fellmann, F.; Horn, D.; Zeviani, M.; Kutsche, K. Mutations in NDUFB11, Encoding a Complex I Component of the Mitochondrial Respiratory Chain, Cause Microphthalmia with Linear Skin Defects Syndrome. Am. J. Hum. Genet. 2015, 96, 640-650. [CrossRef]

5. Morleo, M.; Pramparo, T.; Perone, L.; Gregato, G.; Le Caignec, C.; Mueller, R.F.; Ogata, T.; Raas-Rothschild, A.; De Blois, M.C.; Wilson, L.C.; et al. Microphthalmia with linear skin defects (MLS) syndrome: Clinical, cytogenetic, and molecular characterization of 11 cases. Am. J. Med. Genet. 2005, 137, 190-198. [CrossRef]

6. Wapenaar, M.C.; Bassi, M.T.; Schaefer, L.; Grillo, A.; Ferrero, G.B.; Chinault, A.C.; Ballabio, A.; Zoghbi, H.Y. The genes for X-linked ocular albinism (OA1) and microphthalmia with linear skin defects (MLS): Cloning and characterization of the critical regions. Hum. Mol. Genet. 1993, 2, 947-952. [CrossRef]

7. Wapenaar, M.C.; Schiaffino, M.V.; Bassi, M.T.; Schaefer, L.; Chinault, A.C.; Zoghbi, H.Y.; Ballabio, A. A YAC-based binning strategy facilitating the rapid assembly of cosmid contigs: $1.6 \mathrm{Mb}$ of overlapping cosmids in Xp22. Hum. Mol. Genet. 1994, 3, 1155-1161. [CrossRef]

8. Quaderi, N.A.; Schweiger, S.; Gaudenz, K.; Franco, B.; Rugarli, E.I.; Berger, W.; Feldman, G.J.; Volta, M.; Andolfi, G.; Gilgenkrantz, S.; et al. Opitz G/BBB syndrome, a defect of midline development, is due to mutations in a new RING finger gene on Xp22. Nat. Genet. 1997, 17, 285-291. [CrossRef] 
9. Schaefer, L.; Ballabio, A.; Zoghbi, H.Y. Cloning and characterization of a putative human holocytochrome c-type synthetase gene (HCCS) isolated from the critical region for microphthalmia with linear skin defects (MLS). Genomics 1996, 34, 166-172. [CrossRef]

10. Schwarz, Q.P.; Cox, T.C. Complementation of a yeast CYC3 deficiency identifies an X-linked mammalian activator of apocytochrome c. Genomics 2002, 79, 51-57. [CrossRef] [PubMed]

11. Prakash, S.K.; Paylor, R.; Jenna, S.; Lamarche-Vane, N.; Armstrong, D.L.; Xu, B.; Mancini, M.A.; Zoghbi, H.Y. Functional analysis of ARHGAP6, a novel GTPase-activating protein for RhoA. Hum. Mol. Genet. 2000, 9, 477-488. [CrossRef] [PubMed]

12. Prakash, S.K.; Cormier, T.A.; McCall, A.E.; Garcia, J.J.; Sierra, R.; Haupt, B.; Zoghbi, H.Y.; Van Den Veyver, I.B. Loss of holocytochrome c-type synthetase causes the male lethality of X-linked dominant microphthalmia with linear skin defects (MLS) syndrome. Hum. Mol. Genet. 2002, 11, 3237-3248. [CrossRef] [PubMed]

13. Van Rahden, V.A.; Rau, I.; Fuchs, S.; Kosyna, F.K.; de Almeida, H.L.; Fryssira, H.; Isidor, B.; Jauch, A.; Joubert, M.; Lachmeijer, A.M.A.; et al. Clinical spectrum of females with HCCS mutation: From no clinical signs to a neonatal lethal form of the microphthalmia with linear skin defects (MLS) syndrome. Orphanet J. Rare Dis. 2014, 9, 53. [CrossRef] [PubMed]

14. Wimplinger, I.; Shaw, G.M.; Kutsche, K. HCCS loss-of-function missense mutation in a female with bilateral microphthalmia and sclerocornea: A novel gene for severe ocular malformations? Mol. Vis. 2007, 13, 1475-1482. [PubMed]

15. Ogata, T.; Wakui, K.; Muroya, K.; Ohashi, H.; Matsuo, N.; Brown, D.M.; Ishii, T.; Fukushima, Y. Microphthalmia with linear skin defects syndrome in a mosaic female infant with monosomy for the Xp22 region: Molecular analysis of the Xp22 breakpoint and the X-inactivation pattern. Hum. Genet. 1998, 103, 51-56. [CrossRef]

16. Bernard, D.G.; Gabilly, S.T.; Dujardin, G.; Merchant, S.; Hamel, P.P. Overlapping specificities of the mitochondrial cytochrome c and $\mathrm{c1}$ heme lyases. J. Biol. Chem. 2003, 278, 49732-49742. [CrossRef] [PubMed]

17. Dumont, M.E.; Ernst, J.F.; Hampsey, D.M.; Sherman, F. Identification and sequence of the gene encoding cytochrome c heme lyase in the yeast Saccharomyces cerevisiae. EMBO J. 1987, 6, 235-241. [CrossRef]

18. Zollner, A.; Rodel, G.; Haid, A. Molecular cloning and characterization of the Saccharomyces cerevisiae CYT2 gene encoding cytochrome-c1-heme lyase. Eur. J. BioChem. 1992, 207, 1093-1100. [CrossRef]

19. Indrieri, A.; Conte, I.; Chesi, G.; Romano, A.; Quartararo, J.; Tatè, R.; Ghezzi, D.; Zeviani, M.; Goffrini, P.; Ferrero, I.; et al. The impairment of HCCS leads to MLS syndrome by activating a non-canonical cell death pathway in the brain and eyes. EMBO Mol. Med. 2013, 5, 280-293. [CrossRef]

20. Drenckhahn, J.D.; Schwarz, Q.P.; Gray, S.; Laskowski, A.; Kiriazis, H.; Ming, Z.; Harvey, R.P.; Du, X.J.; Thorburn, D.R.; Cox, T.C. Compensatory growth of healthy cardiac cells in the presence of diseased cells restores tissue homeostasis during heart development. Dev. Cell 2008, 15, 521-533. [CrossRef]

21. Li, P.; Nijhawan, D.; Budihardjo, I.; Srinivasula, S.M.; Ahmad, M.; Alnemri, E.S.; Wang, X. Cytochrome c and dATP-dependent formation of Apaf-1/caspase-9 complex initiates an apoptotic protease cascade. Cell 1997, 91, 479-489. [CrossRef]

22. Rodriguez, J.; Lazebnik, Y. Caspase-9 and APAF-1 form an active holoenzyme. Genes Dev. 1999, 13, 3179-3184. [CrossRef]

23. Wang, C.; Youle, R.J. The Role of Mitochondria in Apoptosis. Annu. Rev. Genet. 2009, 43, 95-118. [CrossRef]

24. Kiryu-Seo, S.; Gamo, K.; Tachibana, T.; Tanaka, K.; Kiyama, H. Unique anti-apoptotic activity of EAAC1 in injured motor neurons. EMBO J. 2006, 25, 3411-3421. [CrossRef]

25. Morleo, M.; Franco, B. Dosage compensation of the mammalian X chromosome influences the phenotypic variability of X-linked dominant male-lethal disorders. J. Med. Genet. 2008, 45, 401-408. [CrossRef]

26. Tsukihara, T.; Aoyama, H.; Yamashita, E.; Tomizaki, T.; Yamaguchi, H.; Shinzawa-Itoh, K.; Nakashima, R.; Yaono, R.; Yoshikawa, $\mathrm{S}$. The whole structure of the 13-subunit oxidized cytochrome c oxidase at 2.8 A. Science 1996, 272, 1136-1144. [CrossRef]

27. Fornuskova, D.; Stiburek, L.; Wenchich, L.; Vinsova, K.; Hansikova, H.; Zeman, J. Novel insights into the assembly and function of human nuclear-encoded cytochrome c oxidase subunits 4, 5a, 6a, 7a and 7b. Biochem. J. 2010, 428, 363-374. [CrossRef]

28. Kadenbach, B.; Hüttemann, M. The subunit composition and function of mammalian cytochrome c oxidase. Mitochondrion 2015, 24, 64-76. [CrossRef] [PubMed]

29. Indrieri, A.; Grimaldi, C.; Zucchelli, S.; Tammaro, R.; Gustincich, S.; Franco, B. Synthetic long non-coding RNAs [SINEUPs] rescue defective gene expression in vivo. Sci. Rep. 2016, 6, 27315. [CrossRef] [PubMed]

30. Carroll, J.; Shannon, R.J.; Fearnley, I.M.; Walker, J.E.; Hirst, J. Definition of the nuclear encoded protein composition of bovine heart mitochondrial complex I: Identification of two new subunits. J. Biol. Chem. 2002. [CrossRef] [PubMed]

31. Vinothkumar, K.R.; Zhu, J.; Hirst, J. Architecture of mammalian respiratory complex I. Nature 2014, 515, 80-84. [CrossRef]

32. Fiedorczuk, K.; Sazanov, L.A. Mammalian Mitochondrial Complex I Structure and Disease-Causing Mutations. Trends Cell Biol. 2018, 28, 835-867. [CrossRef] [PubMed]

33. Vergult, S.; Leroy, B.; Claerhout, I.; Menten, B. Familial cases of a submicroscopic Xp22.2 deletion: Genotype-phenotype correlation in microphthalmia with linear skin defects syndrome. Mol. Vis. 2013, 19, 311-318. [PubMed]

34. Al-Gazali, L.I.; Mueller, R.F.; Caine, A.; Antoniou, A.; McCartney, A.; Fitchett, M.; Dennis, N.R. Two 46,XX,t(X;Y) females with linear skin defects and congenital microphthalmia: A new syndrome at Xp22.3. J. Med. Genet. 1990, 27, 59-63. [CrossRef] [PubMed]

35. Friedman, P.A.; Rao, K.W.; Teplin, S.W.; Aylsworth, A.S. Provisional mapping deletion of the focal dermal hypoplasia (FDH) gene to Xp22.31. Am. J. Hum. Genet. Suppl. 1988, 43, A450.

36. Temple, I.K.; Hurst, J.A.; Hing, S.; Butler, L.; Baraitser, M. De novo deletion of Xp22.2-pter in a female with linear skin lesions of the face and neck, microphthalmia, and anterior chamber eye anomalies. J. Med. Genet. 1990, 27, 56-58. [CrossRef] 
37. Allanson, J.; Richter, S. Linear skin defects and congenital microphthalmia: A new syndrome at Xp22.2. J. Med. Genet. 1991, 28, 143-144. [CrossRef] [PubMed]

38. Gericke, G.S.; Myburgh, E.; Bester, R.; van Rensberg, E.J.; Neethling, E. Further delineation of the Xp22.2-pter sundrome of linear skin lesions, microphthalmia and anterior chamber anomalies. Am. J. Hum. Genet. Suppl. 1991, 49, A271.

39. Lindor, N.M.; Michels, V.V.; Hoppe, D.A.; Driscoll, D.J.; Leavitt, J.A. Xp22.3 microdeletion syndrome with microphthalmia, sclerocornea, linear skin defects, and congenital heart defects. Am. J. Med. Genet. 1992, 44, 61-65. [CrossRef] [PubMed]

40. Naritomi, K.; Izumikawa, Y.; Nagataki, S.; Fukushima, Y.; Wakui, K.; Niikawa, N.; Hirayama, K. Combined Goltz and Aicardi syndromes in a terminal Xp deletion: Are they a contiguous gene syndrome? Am. J. Med. Genet. 1992, 43, 839-843. [CrossRef]

41. Mucke, J.; Hoepffner, W.; Thamm, B.; Theile, H. MIDAS syndrome (microphthalmia, dermal aplasia and sclerocornea): An autonomous entity with linear skin defects within the spectrum of focal hypoplasias. Eur. J. Dermatol. 1995, 5, $197-203$.

42. Eng, A.; Lebel, R.R.; Elejalde, B.R.; Anderson, C.; Bennett, L. Linear facial skin defects associated with microphthalmia and other malformations, with chromosome deletion Xp22.1. J. Am. Acad. Dermatol. 1994, 31, 680-682. [CrossRef]

43. Paulger, B.R.; Kraus, E.W.; Pulitzer, D.R.; Moore, C.M. Xp microdeletion syndrome characterized by pathognomonic linear skin defects on the head and neck. Pediatr. Dermatol. 1997, 14, 26-30. [CrossRef]

44. Camacho, J.A.; Goodman, B.K.; Hamosh, A.; Hurko, O.; Thomas, G.H. MIDAS syndrome in a 46, XX new born with ambiguous genitalia and a cryptic, de novo X;Y translocation. Am. J. Hum. Genet. Suppl. 1997, 61, A93.

45. Kono, T.; Migita, T.; Koyama, S.; Seki, I. Another observation of microphthalmia in an XX male: Microphthalmia with linear skin defects syndrome without linear skin lesions. J. Hum. Genet. 1999, 44, 63-68. [CrossRef]

46. Al-Gazali, L.I.; Mueller, R.F.; Caine, A.; Nennis, N.; Fitchett, M.; Insley, L.; Goodfellow, P.G.; Hultén, M. An XX male and two $\mathrm{t}(\mathrm{X} ; \mathrm{Y})$ females with linear skin defects and congenital microphthalmia: A new syndrome at Xp22.3. J. Med. Genet. 1988, 25, 638-639.

47. Donnenfeld, A.E.; Coyne, M.D.; Beauregard, L.J. Microphthalmia and chorioretinal lesions in a girl with an Xp22.2-pter deletion and partial 3p trisomy: Clinical observations relevant to Aicardi syndrome gene localization. Am. J. Med. Genet. 1990, 37, 182-186. [CrossRef] [PubMed]

48. Thies, U.; Rao, V.V.N.G.; Engel, W.; Schmidtke, J. Physical mapping of two Xp markers DXS16 and DXS143. Hum. Genet. 1991, 86, 418-420. [CrossRef] [PubMed]

49. Koyama, S.; Kono, T.; Uchida, K.; Noguchi, E.; Suzuki, K.; Yamasuge, M.; Otsuka, M.; Ito, M.; Suzuki, M.; Migita, T.; et al. XX male with ocular symptoms [Japanese]. Presented at the 34th Annual Meetingof the Japanese Teratology Society at Kochi, Japan. Congenit. Anom. 1993, 34, B-04.

50. Stratton, R.F.; Walter, C.A.; Paulgar, B.R.; Price, M.E.; Moore, C.M. Second 46,XX males with MLS syndrome. Am. J. Med. Genet. 1998, 76, 37-41. [CrossRef]

51. Kayserili, H.; Cox, T.C.; Cox, L.L.; Basaran, S.; Kilic, G.; Ballabio, A.; Yuksel-Apak, M. Molecular characterisation of a new case of microphthalmia with linear skin defects (MLS). J. Med. Genet. 2001, 38, 411-417. [CrossRef]

52. Kutsche, K.; Werner, W.; Bartsch, O.; von der Wense, A.; Meinecke, P.; Gal, A. Microphthalmia with linear skin defects syndrome (MLS): A male with a mosaic paracentric inversion of Xp. CytoGenet. Genome Res. 2002, 99, 297-302. [CrossRef]

53. Anguiano, A.; Yang, X.; Felix, J.K.; Hoo, J.J. Twin brothers with MIDAS syndrome and XX karyotype. Am. J. Med. Genet. 2003, 119A, 47-49. [CrossRef]

54. Enright, F.; Campbell, P.; Stallings, R.L.; Hall, K.; Green, A.J.; Sweeney, E.; Barnes, L.; Watson, R. Xp22.3 microdeletion in a 19-year-old girl with clinical features of MLS syndrome. Pediatr. Dermatol. 2003, 20, 153-157. [CrossRef]

55. Cape, C.J.; Zaidman, G.W.; Beck, A.D.; Kaufman, A.H. Phenotypic variation in ophthalmic manifestations of MIDAS syndrome (microphthalmia, dermal aplasia, and sclerocornea). Arch. OphthalMol. 2004, 122, 1070-1074. [CrossRef]

56. Cain, C.C.; Saul, D.; Attanasio, L.; Oehler, E.; Hamosh, A.; Blakemore, K.; Stetten, G. Microphthalmia with linear skin defects (MLS) syndrome evaluated by prenatal karyotyping, FISH and array comparative genomic hybridization. Prenat. Diagn. 2007, 27, 373-379. [CrossRef]

57. Sharma, V.M.; Ruiz de Luzuriaga, A.M.; Waggoner, D.; Greenwald, M.; Stein, S.L. Microphthalmia with linear skin defects: A case report and review. Pediatr. Dermatol. 2008, 25, 548-552. [CrossRef] [PubMed]

58. Hobson, G.M.; Gibson, C.W.; Aragon, M.; Yuan, Z.A.; Davis-Williams, A.; Banser, L.; Kirkham, J.; Brook, A.H. A large Xchromosomal deletion is associated with microphthalmia with linear skin defects (MLS) and amelogenesis imperfecta (XAI). Am. J. Med. Genet. A 2009, 149A, 1698-1705. [CrossRef] [PubMed]

59. Alberry, M.S.; Juvanic, G.; Crolla, J.; Soothill, P.; Newbury-Ecob, R. Pseudotail as a feature of microphthalmia with linear skin defects syndrome. Clin. Dysmorphol. 2011, 20, 111-113. [CrossRef] [PubMed]

60. Zumwalt, J.; Moorhead, C.; Golkar, L. Fourteen-month-old girl with facial skin thinning. Pediatr. Dermatol. 2012, $29,217-218$. [CrossRef]

61. Steichen-Gersdorf, E.; Griesmaier, E.; Pientka, F.K.; Kotzot, D.; Kutsche, K. A severe form of the X-linked microphthalmia with linear skin defects syndrome in a female newborn. Clin. Dysmorphol. 2010, 19, 82-84. [CrossRef] [PubMed]

62. Wimplinger, I.; Rauch, A.; Orth, U.; Schwarzer, U.; Trautmann, U.; Kutsche, K. Mother and daughter with a terminal Xp deletion: Implication of chromosomal mosaicism and X-inactivation in the high clinical variability of the microphthalmia with linear skin defects (MLS) syndrome. Eur. J. Med. Genet. 2007, 50, 421-431. [CrossRef] [PubMed] 
63. Margari, L.; Colonna, A.; Craig, F.; Gentile, M.; Giannella, G.; Lamanna, A.L.; Legrottaglie, A.R. Microphthalmia with Linear Skin Defects (MLS) associated with Autism Spectrum Disorder (ASD) in a patient with Familial 12.9Mb Terminal Xp deletion. BMC Pediatr. 2014, 14, 1-5. [CrossRef]

64. Kluger, N.; Bouissou, A.; Tauzin, L.; Puechberty, J.; Dereure, O. Congenital Linear Streaks on the Face and Neck and Microphthalmia in an Infant Girl. Acta Derm. Venereol. 2014, 94, 342-343. [CrossRef] [PubMed]

65. Prepeluh, N.; Korpar, B.; Zagorac, A.; Zagradišnik, B.; Golub, A.; Kokal, J.; Vokač, N. A mosaic form of microphthalmia with linear skin defects. BMC Pediatr. 2018, 18, 254. [CrossRef] [PubMed]

66. Kumar, P.; Rajab, A. Microphthalmia with linear skin defects (MLS) syndrome: Familial presentation. Clin. Exp. Dermatol. 2018, 43, 196-197. [CrossRef]

67. Satcher, K.G.; Maegawa, G.H.B.; Schoch, J.J. Microphthalmia and linear skin defects syndrome: Precise diagnosis guides prognosis. Pediatr. Dermatol. 2020, 37, 217-218. [CrossRef]

68. Vendramini-Pittoli, S.; Candido-Souza, R.M.; Quiezi, R.G.; Zechi-Ceide, R.M.; Kokitsu-Nakata, N.M.; Jehee, F.S.; Ribeiro-Bicudo, L.A.; FitzPatrick, D.R.; Guion-Almeida, M.L.; Richieri-Costa, A. Microphthalmia, Linear Skin Defects, Callosal Agenesis, and Cleft Palate in a Patient with Deletion at Xp22.3p22.2. J. Pediatr. Genet. 2020, 09, 258-262. [CrossRef]

69. De Almeida, H.L., Jr.; Rossi, G.; de Abreu, L.B.; Bergamaschi, C.; da Silva, A.B.; Kutsche, K. Dermatoscopic aspects of the Microphthalmia with Linear Skin Defects (MLS) Syndrome. An. Bras. Dermatol. 2014, 89, 180-181. [CrossRef]

70. Durack, A.; Mehta, S.G.; Allen, L.E.; Ozanic Bulic, S.; Burrows, N.P. Linear skin defects and microphthalmia. Clin. Exp. Dermatol. 2018, 43, 860-862. [CrossRef]

71. Kapur, R.; Tu, E.Y.; Toyran, S.; Shah, P.; Vangveeravong, S.; Lloyd, W.C., 3rd; Edward, D.P. Corneal pathology in microphthalmia with linear skin defects syndrome. Cornea 2008, 27, 734-738. [CrossRef]

72. Feichtinger, R.G.; Sperl, W.; Bauer, J.W.; Kofler, B. Mitochondrial dysfunction: A neglected component of skin diseases. Exp. Dermatol. 2014, 23, 607-614. [CrossRef]

73. Rea, G.; Homfray, T.; Till, J.; Roses-Noguer, F.; Buchan, R.J.; Wilkinson, S.; Wilk, A.; Walsh, R.; John, S.; McKee, S.; et al. Histiocytoid cardiomyopathy and microphthalmia with linear skin defects syndrome: Phenotypes linked by truncating variants in NDUFB11. Mol. Case Stud. 2017, 3, a001271. [CrossRef]

74. Shehata, B.M.; Cundiff, C.A.; Lee, K.; Sabharwal, A.; Lalwani, M.K.; Davis, A.K.; Agrawal, V.; Sivasubbu, S.; Iannucci, G.J.; Gibson, G. Exome sequencing of patients with histiocytoid cardiomyopathy reveals a de novo NDUFB11 mutation that plays a role in the pathogenesis of histiocytoid cardiomyopathy. Am. J. Med. Genet. Part A 2015, 167, 2114-2121. [CrossRef]

75. Kohda, M.; Tokuzawa, Y.; Kishita, Y.; Nyuzuki, H.; Moriyama, Y.; Mizuno, Y.; Hirata, T.; Yatsuka, Y.; Yamashita-Sugahara, Y.; Nakachi, Y.; et al. A Comprehensive Genomic Analysis Reveals the Genetic Landscape of Mitochondrial Respiratory Chain Complex Deficiencies. PLoS Genet. 2016, 12, e1005679. [CrossRef] [PubMed]

76. Lichtenstein, D.A.; Crispin, A.W.; Sendamarai, A.K.; Campagna, D.R.; Schmitz-Abe, K.; Sousa, C.M.; Kafina, M.D.; Schmidt, P.J.; Niemeyer, C.M.; Porter, J.; et al. A recurring mutation in the respiratory complex 1 protein NDUFB11 is responsible for a novel form of X-linked sideroblastic anemia. Blood 2016, 128, 1913-1917. [CrossRef]

77. Torraco, A.; Bianchi, M.; Verrigni, D.; Gelmetti, V.; Riley, L.; Niceta, M.; Martinelli, D.; Montanari, A.; Guo, Y.; Rizza, T.; et al. A novel mutation in NDUFB11 unveils a new clinical phenotype associated with lactic acidosis and sideroblastic anemia. Clin. Genet. 2017, 91, 441-447. [CrossRef] [PubMed]

78. Franco, B.; Meroni, G.; Parenti, G.; Levilliers, J.; Bernard, L.; Gebbia, M.; Cox, L.; Maroteaux, P.; Sheffield, L.; Rappold, G.A.; et al. A cluster of sulfatase genes on Xp22.3: Mutations in chondrodysplasia punctata (CDPX) and implications for warfarin embryopathy. Cell 1995, 81, 15-25. [CrossRef]

79. Parenti, G.; Rizzolo, M.G.; Ghezzi, M.; Di Maio, S.; Sperandeo, M.P.; Incerti, B.; Franco, B.; Ballabio, A.; Andria, G. Variable penetrance of hypogonadism in a sibship with Kallmann syndrome due to a deletion of the KAL gene. Am. J. Med. Genet. 1995, 57, 476-478. [CrossRef] [PubMed]

80. Franco, B.; Guioli, S.; Pragliola, A.; Incerti, B.; Bardoni, B.; Tonlorenzi, R.; Carrozzo, R.; Maestrini, E.; Pieretti, M.; Taillon-Miller, P.; et al. A gene deleted in Kallmann's syndrome shares homology with neural cell adhesion and axonal path-finding molecules. Nature 1991, 353, 529-536. [CrossRef]

81. Ferrante, M.I.; Feather, S.A.; Bulfone, A.; Wright, V.; Ghiani, M.; Selicorni, A.; Gammaro, L.; Scolari, F.; Woolf, A.S.; Sylvie, O.; et al. Identification of the Gene for Oral-Facial-Digital Type I Syndrome. Am. J. Hum. Genet. 2001, 68, 569-576. [CrossRef]

82. Khonsari, R.H.; Seppala, M.; Pradel, A.; Dutel, H.; Clément, G.; Lebedev, O.; Ghafoor, S.; Rothova, M.; Tucker, A.; Maisey, J.G.; et al. The buccohypophyseal canal is an ancestral vertebrate trait maintained by modulation in sonic hedgehog signaling. BMC Biol. 2013, 11, 27. [CrossRef]

83. Reinson, K.; Kovacs-Nagy, R.; Õiglane-Shlik, E.; Pajusalu, S.; Nõukas, M.; Wintjes, L.T.; van den Brandt, F.C.A.; Brink, M.; Acker, T.; Ahting, U.; et al. Diverse phenotype in patients with complex I deficiency due to mutations in NDUFB11. Eur. J. Med. Genet. 2019, 62, 103572. [CrossRef]

84. Lyon, M.F. Gene action in the X-chromosome of the mouse (Mus musculus L.). Nature 1961, 190, 372-373. [CrossRef]

85. Migeon, B.R. X-linked diseases: Susceptible females. Genet. Med. 2020, 22, 1156-1174. [CrossRef]

86. Franco, B.; Ballabio, A. X-inactivation and human disease: X-linked dominant male-lethal disorders. Curr. Opin. Genet. Dev. 2006, 16, 254-259. [CrossRef]

87. Munnich, A.; Rustin, P. Clinical spectrum and diagnosis of mitochondrial disorders. Am. J. Med. Genet. 2001, 106, 4-17. [CrossRef] 
88. DiMauro, S.; Tanji, K.; Schon, E.A. Mitochondrial Encephalomyopathies 尔. In Reference Module in Neuroscience and Biobehavioral Psychology; Elsevier: Amsterdam, The Netherlands, 2017; ISBN 9780128093245.

89. Chinnery, P.F. Mitochondrial Disorders Overview; University of Washington: Seattle, WA, USA, 1993.

90. Birch-Machin, M.A. Mitochondria and skin disease. Clin. Exp. Dermatol. 2000, 25, 141-146. [CrossRef] [PubMed]

91. Misgeld, T.; Schwarz, T.L. Mitostasis in Neurons: Maintaining Mitochondria in an Extended Cellular Architecture. Neuron 2017, 96, 651-666. [CrossRef] [PubMed]

92. Yamaguchi, Y.; Miura, M. Programmed Cell Death in Neurodevelopment. Dev. Cell 2015, 32, 478-490. [CrossRef] [PubMed]

93. Hagberg, H.; Mallard, C.; Rousset, C.I.; Thornton, C. Mitochondria: Hub of injury responses in the developing brain. Lancet Neurol. 2014, 13, 217-232. [CrossRef] 